\title{
Analysis and prospects of container and rail transport
}

\author{
Sergey Vakulenko ${ }^{1, *}$, Pyotr Kurenkov ${ }^{1}$, Dmitry Romensky ${ }^{1}$, Kirill Kalinin ${ }^{1}$, and Jozef \\ Gašparík ${ }^{2}$ \\ ${ }^{1}$ Department of Transport business management and intelligent systems, Russian University of \\ Transport, Moscow, Obraztsova str., 9, building 9, 127994. Russia \\ ${ }^{2}$ Faculty of Operation and Economics of Transport and Communications, Zilina, Univerzitná 8215/1, \\ 010 26, Republic of Slovakia
}

\begin{abstract}
The article studies the main trends in the market of container transportation in rolling stock of various types, considers the process of transporting large-capacity containers in open wagons. The operational and economic aspects of removing administrative restrictions on the implementation of this type of transportation are noted. The dynamics of rental rates for rental of gondola cars and platforms in 2019-2020 is present. The summary characteristics of the gondola car fleet and fitting platforms on the Russian Railways network have been study. The analysis of the market share of the largest owners of gondola cars and fitting platforms was carry out. The advantages and disadvantages of using the technology of container transportation in open wagons are list. Solutions are propose to create a competitive environment in the container transportation segment of the transport services market.
\end{abstract}

\section{Introduction}

Currently, containers are transport on fitting platforms, but theoretically, according to international rules, they can also be transport in open wagons: 40-feet - horizontally per piece, 20-feet - two each, and empty 20 -feet - even three.

From December 1, 2014, the local technical conditions (LTC) for the placement and fastening of universal containers in gondola cars with unloading hatches were cancel. Thus, the transportation of containers in open wagons was banned [1].

In the telegram of JSC "Russian Railways" it was indicated that the existing LTC were cancel, since as a result of experimental tests of the reliability of the methods of placing and securing universal containers in gondola cars with and without unloading hatches, it was established that the methods of stowing and securing goods provided for by LTC did not ensure the safety of the cars containers.

The idea of transporting containers in open wagons is not new. Until 2014, such transportation was practiced on the railway network in Russia, however, in early August 2014, Rostransnadzor introduced a ban on the transportation of containers in gondola cars, but after meetings initiated by the Council of Railway Transport Operators, the ban was

\footnotetext{
* Corresponding author: iuit@miit.ru
} 
lifted and from the end of August OJSC Russian Railways "accepted applications for transportation in open wagons in full.

In 2020, the situation on the railways has change: a surplus of the fleet and sluggish market conditions have led to the fact that hundreds of thousands of gondola cars are idle.

An important factor is that the restrictive measures introduced by the holding in 2014 were aim at stimulating the containerization of goods and the development of PJSC TransContainer, which at that time was a subsidiary of Russian Railways. At the end of 2019, Russian Railways parted with TransContainer, which was acquired for RUB 60.3 billion. by the group of companies "Delo" by Sergey Shishkarev [2].

To date, a categorical ban on the carriage of containers in open wagons in domestic traffic is not justified for the following reasons:

1) there is no or not published comprehensive information on the facts of the negative impact of the carriage of large-capacity containers in open wagons on traffic safety, including the impact on infrastructure or rolling stock;

2) the possibility of loading and transporting large-tonnage containers in open wagons is provided for in Appendix 14 to the Agreement on International Rail freight traffic "Rules for stowing and securing goods in wagons and containers (Chapter 9" Stowing and securing containers and swap bodies ").

Design institutes OJSC «All-Russian Research Institute of Railway Transport " together with OJSC "Russian Railways" carried out experimental checks (impact tests) of the reliability of methods for placing and fastening universal containers in gondola cars, which showed that the methods of placing and securing goods do not ensure the safety of cars and containers. Additional analysis and retesting could identify the scope of applicability of container transportation in open wagons and determine the limits on the speed of dissolution from humps [3].

Transportation of containers in a universal rolling stock has its advantages and disadvantages. Gradually, there was a transition from the use of container transportation in open wagons on main routes to the use of such transportation in one-time shipments on an individual basis [4].

In the Russian practice of using the technology for transporting containers in gondola cars, a certain specificity was observed: during the period of general economic decline in the 90 s and early 2000s, when there were no funds for the bulk purchase of specialized fitting platforms and there was no well-established technology for working with container trains [5]. As a result, gondola cars and covered wagons of the old series with wooden walls were re-equipped for the transportation of medium and large-capacity containers. Then such transportation was ubiquitous and it was then that the practice of transporting containers appeared in the renewed fleet of gondola cars.

The situation with the specific development of the market for container transportation in open wagons has developed due to a number of conditions in which the Ministry of Railways of Russia existed, and then Russian Railways:

- a significant reduction in traffic volumes;

- lack of funds to renew the car fleet;

- changes in the structure of transportation;

- a decrease in the attractiveness of medium-tonnage containers.

According to JSC "Russian Railways", on June 25, new tests of placement and fastening of large-tonnage containers in gondola cars began, following the order of Dmitry Gorokh, Deputy Head of the Russian Railways Central Transport Service Center.

Foreign containers in foreign open wagons transported today. But the tests will take place against the backdrop of a heated discussion about whether to return this practice in Russia, which has already been supported by the head of Russian Railways, Oleg Belozerov. 
In January - May 2020, 665 transit containers passed through the Russian Railways network and 804 imported containers arrived in Russia.

The purpose of the tests is to test new types of fasteners used abroad for fastening containers inside the car, for their compliance with Russian requirements safely

\section{Materials and Methods}

The development of internal competition on the railway network between operators of different rolling stock can create preconditions for the technological and structural development of platforms and gondola cars. For example, the railway network already has platform wagons adapted both for the transportation of long loads (pipes, lumber) and for the transportation of containers, and for the gondola car market, a similar issue of introducing wagons equipped with stationary or removable fitting stops can be considered.

The works of such authors as Buda M., Kudlac, S., Kurenkov P., Majercak J., Pokrovskaya O. are devoted to the development of the container transportation market.

The purpose of the publication is to analyze scientific literature and research results on the development of the container transportation market in order to develop recommendations for increasing the competitiveness of rail transport and reducing the cost of rail transportation. The study used the following methods: systematic approach, structural analysis, analysis of official statistics, document analysis method, abstract-logical method, ranking method.

\section{Results}

Transportation by the proposed LTC is associated with a significant increase in the labor intensity and duration of cargo operations at container terminals due to the absence of fitting stops in the gondola cars. The proposed procedure provides for manual fixing of containers to the car floor using bars, spacers and linings, for which a team of loaders must handle the handling of each car, which increases the need for personnel at the station. Securing the container is associated with long and unsafe rigging work [6]. As a guarantee of the absence of longitudinal and transverse movements of the container, it is proposed to use pneumatic cushions (pneumatic cushions), which can be damaged by sharp corners and burrs on the metal walls of cars and containers. Nevertheless, the reasoning of the transport scientific and industrial community that such transportation is extremely unsafe, and the proposed LTC do not take into account any specific loads, we consider insignificant, since LTC can be tested, modified and somehow implemented, provided reliable fastening of the container in the gondola car [7]. That is, if the rules for the transportation of goods and containers are compulsory, it is technically safe to place a container.

Rental rates for rolling stock lease have significantly decreased for all types of rolling stock compared to the beginning of the year and the level of 2019.

The dynamics of rental rates for gondola cars and flatcars for 2019 and the first 6 months of 2020 is show in Figures 1 and 2. 


\section{ICMTMTE 2020}

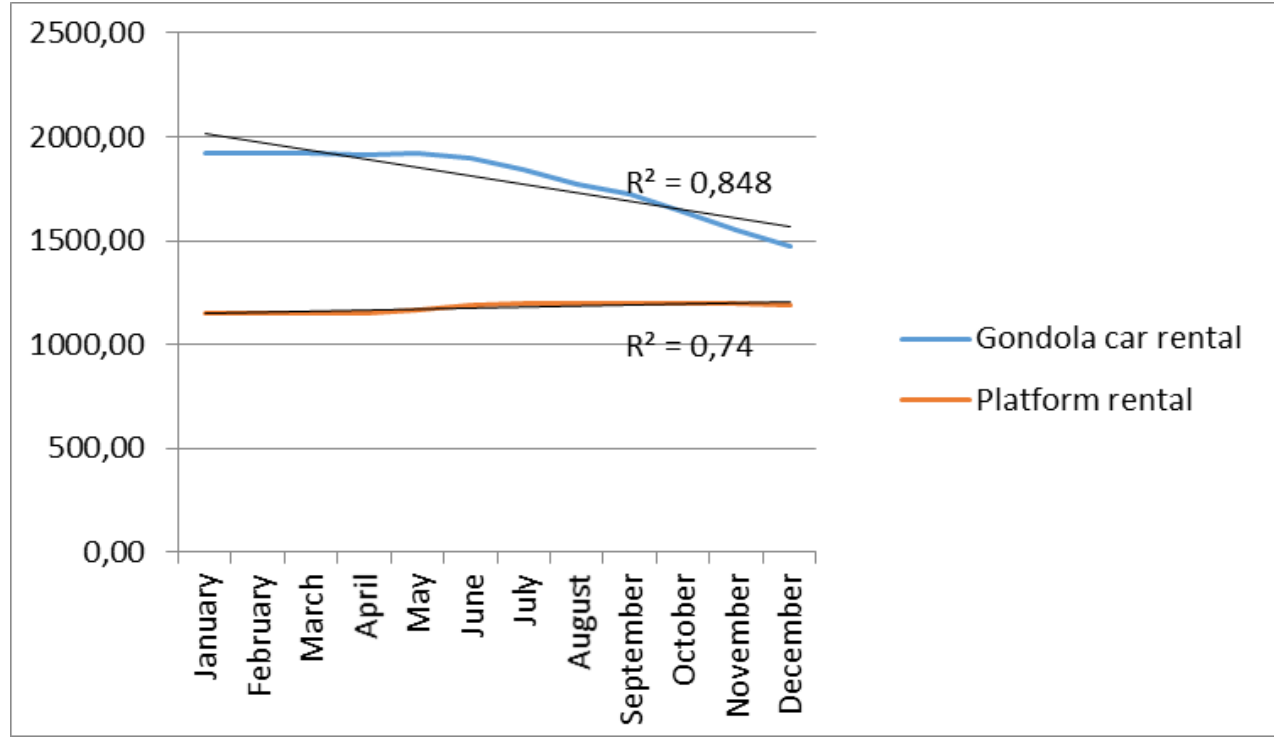

Fig. 1. Average rental rate for rolling stock in 2019.

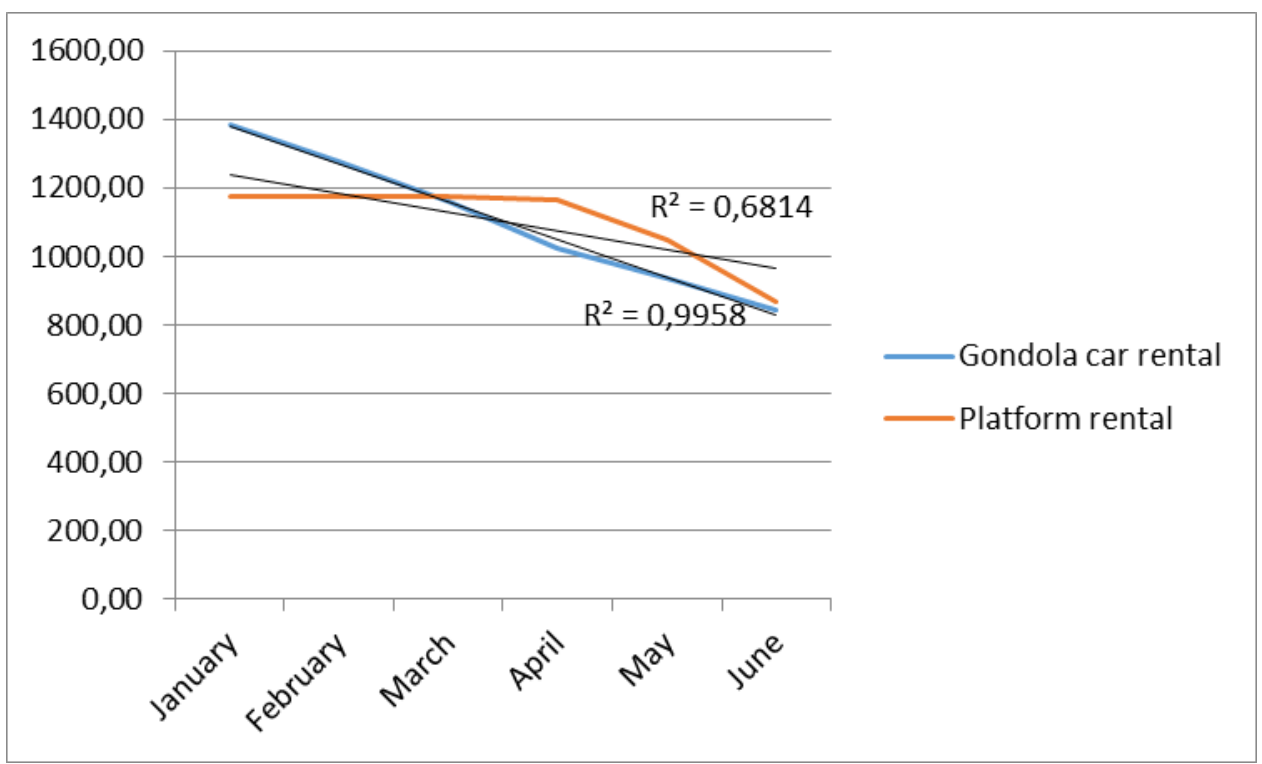

Fig. 2. Average rental rate for rolling stock for January-June 2020.

From the above data, it follows that the average rental rate for open-top wagons by June 2020 dropped below the average rental rate for a platform, which is not a typical state of rental rates in recent years. For the period 2019-2020, the gondola car rental rate dropped from RUB 1925 per day. up to 845 rubles / day - the rate reduction was $56.1 \%$, for platforms for the same period the rate decreased from 1200 to 875 i.e. by $27.5 \%$. This decline was due to a significant decrease in demand with a continuous increase in the number of rolling stock. Today almost 100,000 wagons are idle on the railway network. By the end of last year, even before the reduction in loading caused by quarantine measures and the shutdown of a number of enterprises, the excess of the fleet was estimate at $12 \%$ of the entire railway fleet. At the same time, from January to June 2020, the network received 
14,200 new cars. An excess of rolling stock and a reduction in the cargo base will inevitably lead to the impossibility of servicing lease payments by some operators and subsequent bankruptcies. A decrease in demand for transportation in gondola cars will, in turn, lead to a drop in orders for new rolling stock due to oversaturation of the secondary market, in the event of a protracted drop in demand for transportation in gondola cars, this can lead to aging of the gondola wagon fleet on the network [8].

The ownership structure of the rolling stock fleet is not uniform and has its own characteristics for gondola cars and fitting platforms. The rolling stock can be directly own either by the carrier or lease.

The quantitative characteristics of the gondola car fleet and fitting platforms are show in Tables 1 and 2.

Table 1. Summary characteristics of the gondola car fleet on the Russian Railways network

\begin{tabular}{|c|c|c|}
\hline \multirow[t]{2}{*}{ Parameter } & \multicolumn{2}{|c|}{ Parameter value } \\
\hline & Absolute & Lobar \\
\hline \multicolumn{3}{|c|}{ Gondolas } \\
\hline Gondola cars on the network total & 523033 & 100,0 \\
\hline \multicolumn{3}{|c|}{ Distribution of gondola cars by form of ownership } \\
\hline Number of wagons at the carrier & 218428 & 41,76 \\
\hline The number of cars the leasing companies & 284056 & 54,31 \\
\hline \multicolumn{3}{|c|}{ Distribution of gondola cars by number of owners } \\
\hline Number of wagons at the carrier & 48 & 52,17 \\
\hline The number of cars the leasing companies & 44 & 47,83 \\
\hline \multicolumn{3}{|c|}{ The largest owners of rolling stock } \\
\hline JSC "FGC" & 66975 & 12,81 \\
\hline JSC "PGK" & 38810 & 7,42 \\
\hline "SBERBANK LEASING" JSC & 38313 & 7,33 \\
\hline "VTB LEASING" JSC & 36447 & 6,97 \\
\hline "VEB-LEASING" JSC & 31069 & 5,94 \\
\hline
\end{tabular}

Table 2. Summary characteristics of the fleet of fitting platforms on the Russian Railways network

\begin{tabular}{|c|c|c|}
\hline \multirow[t]{2}{*}{ Parameter } & \multicolumn{2}{|c|}{ Parameter value } \\
\hline & Absolute & Lobar \\
\hline \multicolumn{3}{|c|}{ Fitting platform } \\
\hline Fitting platforms on the network total & 61068 & 100,0 \\
\hline \multicolumn{3}{|c|}{ Distribution of gondola cars by form of ownership } \\
\hline Number of wagons at the carrier & 42704 & 69,93 \\
\hline The number of cars the leasing companies & 16238 & 26,59 \\
\hline \multicolumn{3}{|c|}{$\begin{array}{c}\text { Distribution of gondola cars by number of owners } \\
\end{array}$} \\
\hline Number of carrier owners & 53 & 57,61 \\
\hline The number of owners - lessors & 32 & 34,78 \\
\hline \multicolumn{3}{|c|}{$\begin{array}{ll}\text { The largest owners of rolling stock } \\
\end{array}$} \\
\hline PJSC "TRANSCONTAINER" & 27223 & 44,58 \\
\hline OOO "RENSVIK RAIL" & 4235 & 6,93 \\
\hline PJSC "GTLK" & 4071 & 6,67 \\
\hline "VEB LEASING" JSC & 1998 & 3,27 \\
\hline "RUSSIAN TROIKA" JSC & 1473 & 2,41 \\
\hline
\end{tabular}

The structure of the gondola car fleet by ownership is show in Figure 3, the distribution by the number of owners in the market in Figure 4, and the mass share of the largest players in Figure 5. 


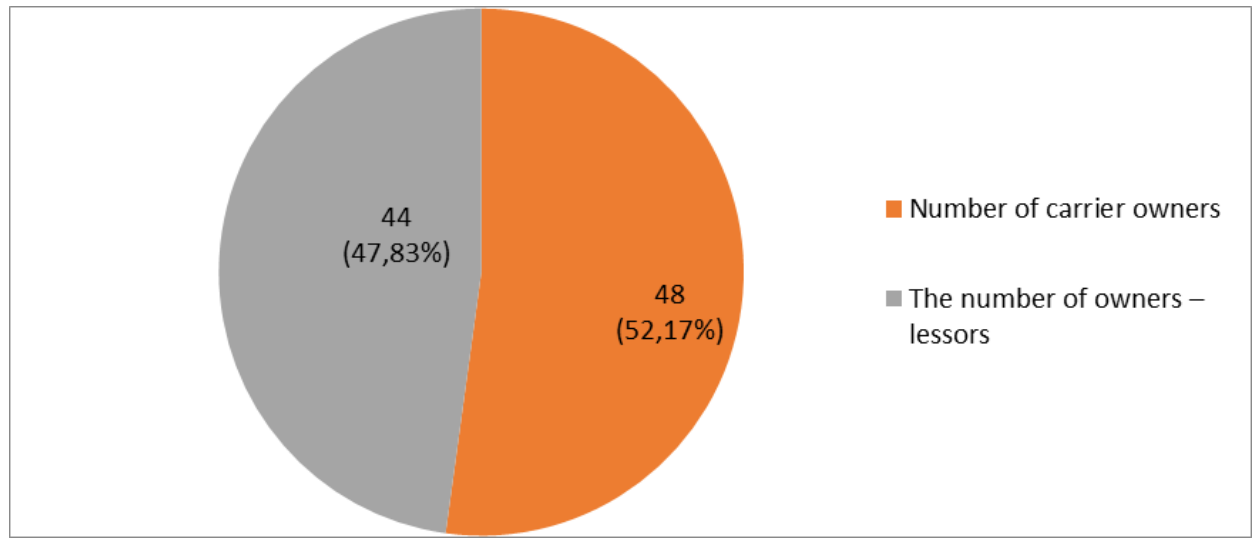

Fig. 3. Distribution of the gondola car fleet by form of ownership

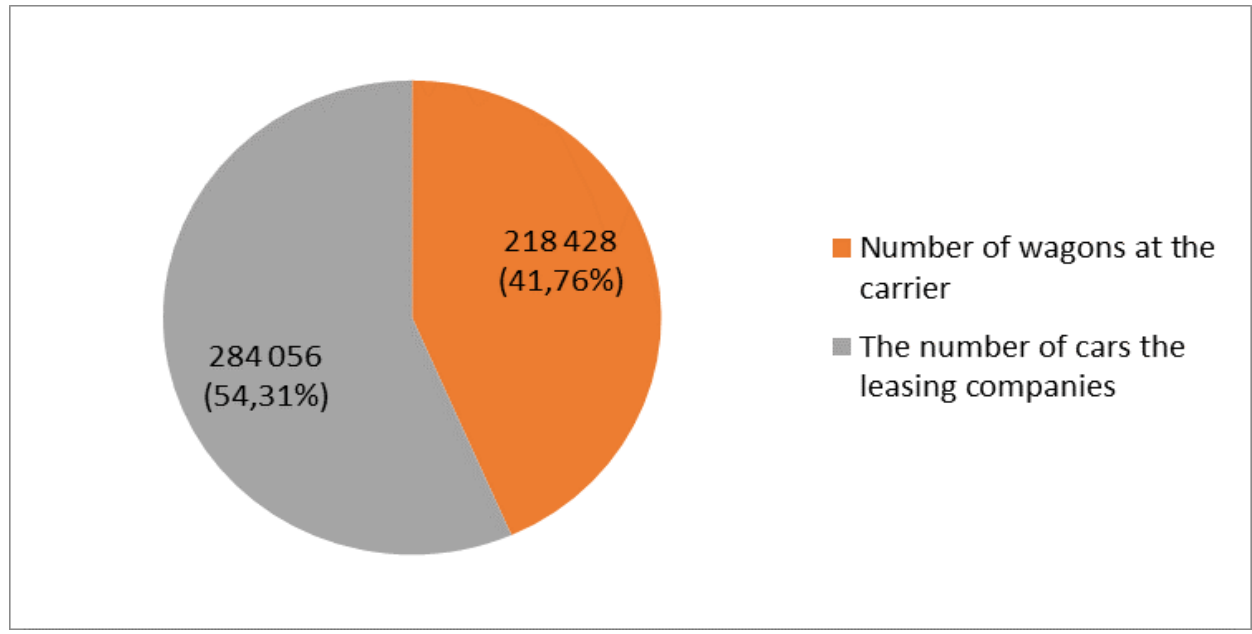

Fig. 4. Distribution of the gondola car fleet by the number of owners

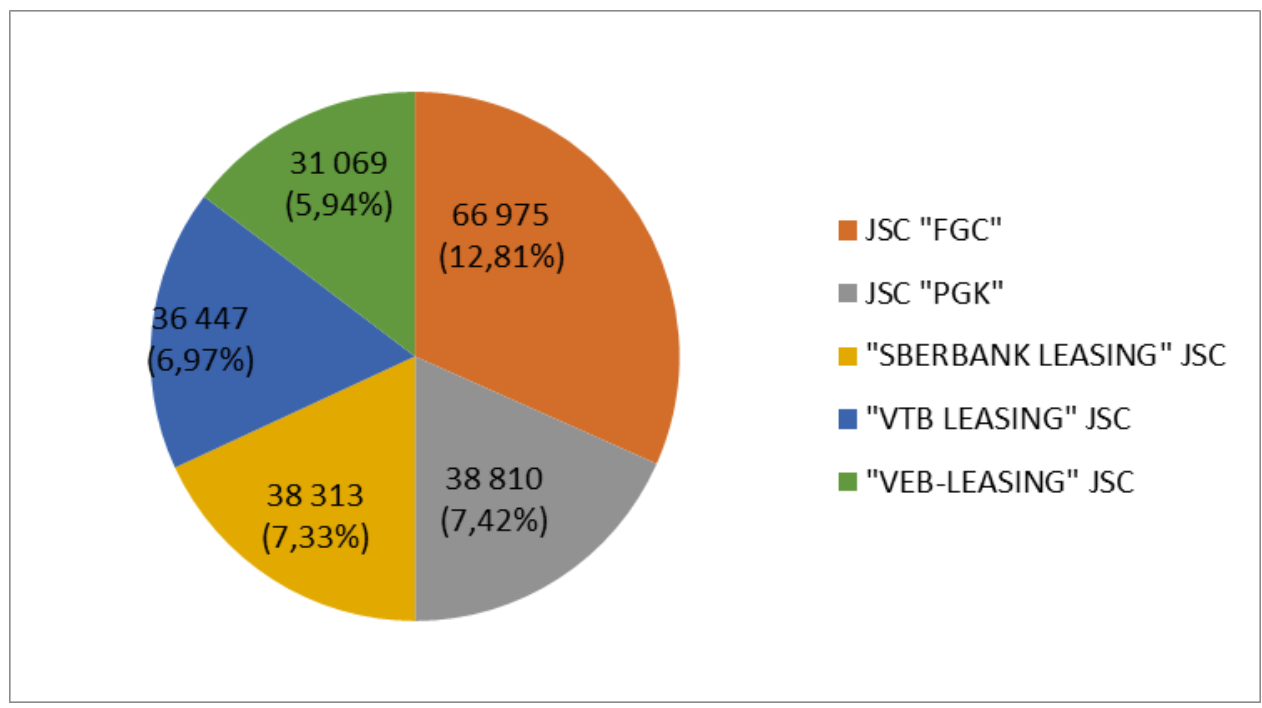

Fig. 5. Analysis of the market share of the largest gondola car owners 
The structure of the fleet of fitting platforms by form of ownership is show in Figure 6, the distribution by the number of owners in the market in Figure 7, the mass share of the largest players in Figure 8.

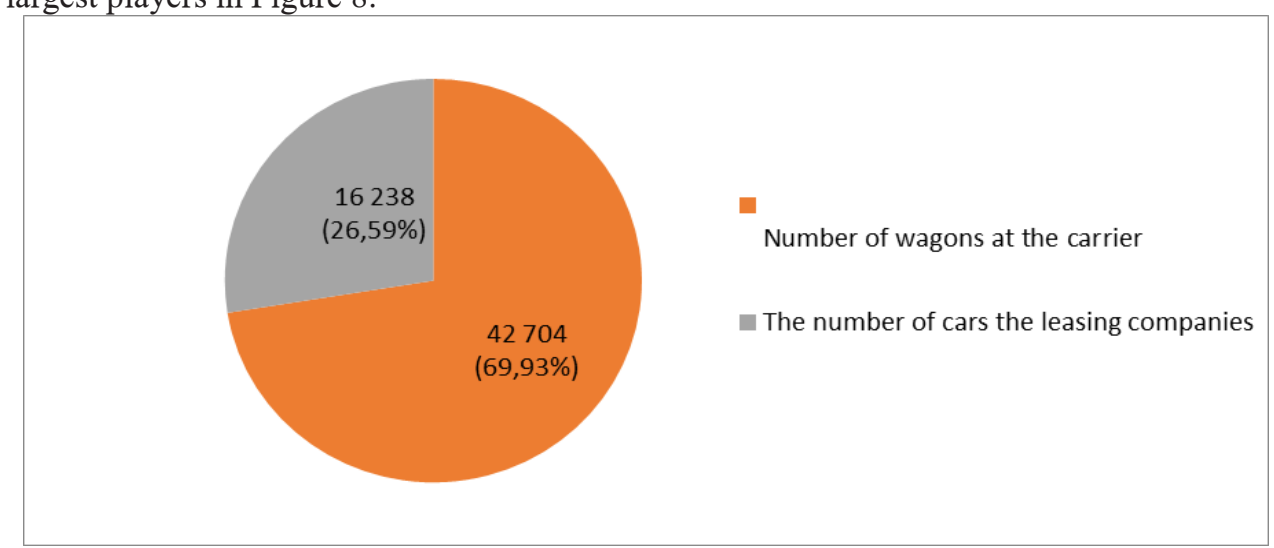

Fig. 6. Distribution of the fleet of fitting platforms by ownership

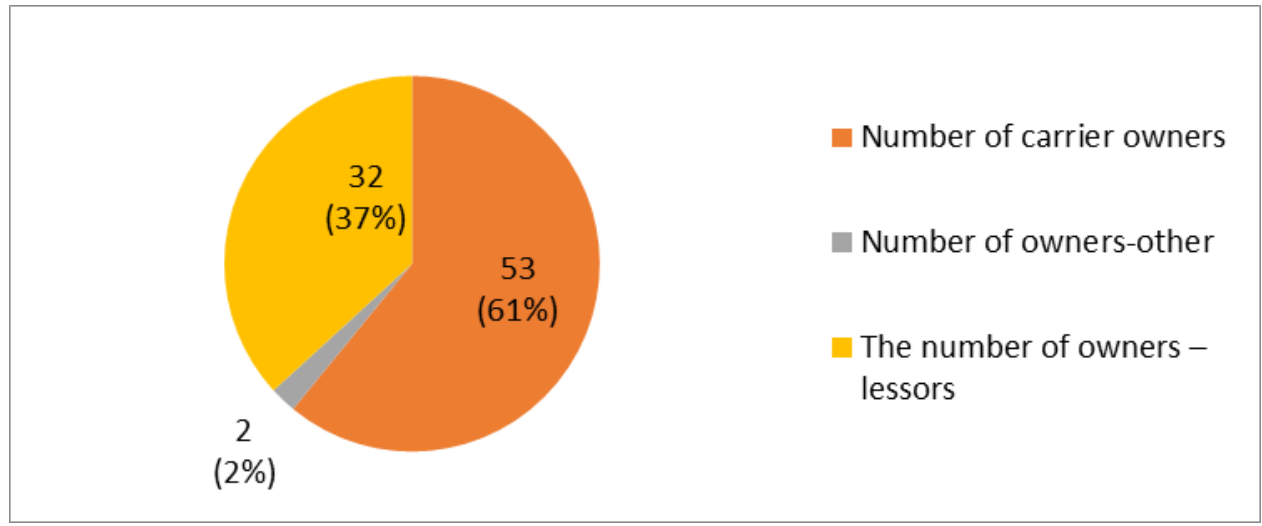

Fig. 7. Distribution of the fleet of fitting platforms by the number of owners.

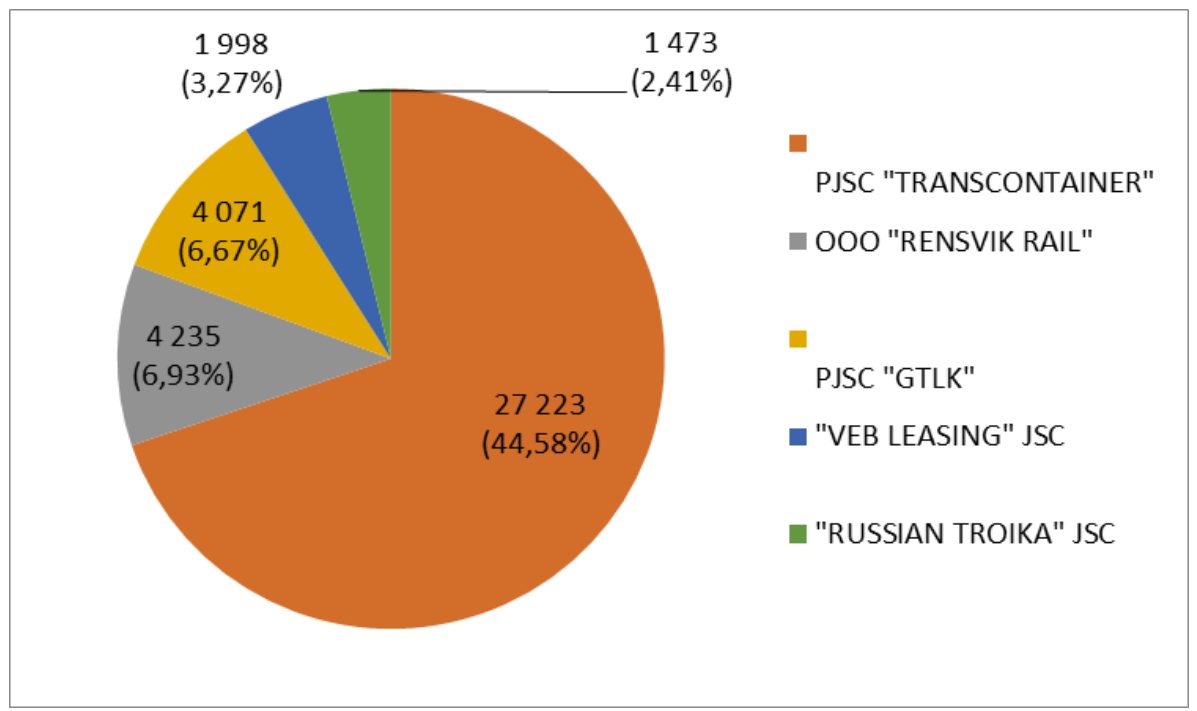

Fig. 8. Analysis of the market share of the largest owners of fitting platforms. 
Analyzing the situation on the market of gondola cars and fitting platforms, one can come to the following conclusions:

1) 92 gondola car operators manage more than $95 \%$ of rolling stock. Of these, $57 \%$ of cars are lease and the carrier directly owns $43 \% .80 \%$ of the rolling stock is distributed in comparable proportions among 19 rolling stock operators. The largest operators are AO FGK, AO Freight One and AO Sberbank Leasing, they own $27.55 \%$ of the gondola car fleet.

2) more than $95 \%$ of rolling stock is managed by 65 operators of fitting platforms. Of these, $37 \%$ of platforms are leased and $61 \%$ are directly owned by the carrier. $80 \%$ of the rolling stock is unevenly distributed among 17 rolling stock operators. The largest operator is PJSC Transcontainer, which controls $45 \%$ of the fleet of fitting platforms, while other players in the market of fitting platforms have no more than $7 \%$ of rolling stock at their disposal.

Advantages of using the technology of container transportation in open wagons:

1) involvement of gondola cars in servicing container transportation to improve the operational performance of gondola cars when servicing import traffic, and to reduce the network coefficient of empty run of a wagon;

2) the use of gondola cars for container transportation will allow attracting shippers for the transportation of containers by rail to those stations of the network that do not have the necessary technical equipment to work with container trains, or, if the necessary technical equipment is available, do not accept regular container routes due to the lack of the necessary the amount of container traffic;

3) the removal of the administrative barrier on the use of gondola cars for container transportation will create a situation of possible competition between operators of gondola cars and operators of fitting platforms for adjacent geographical transportation markets. The development of competition, in turn, will lead to an increase in the quality of container transportation on fitting platforms by stimulating the introduction of new transportation technologies and organizing the passage of container trains (for example, "Freight Express", "Cold Express");

4) the creation of a competitive environment can lead to the emergence of new hybrid types of rolling stock, which will take into account the disadvantages of fitting platforms and gondola cars.

Disadvantages of using the technology for transporting containers in open wagons:

1) for the carrier, the acceptance of a gondola car with containers for transportation by the receiver is associated with increased labor intensity, since the fastening of the container must be checked for compliance with the current transportation rules in conditions of difficult access to the container [9];

2) the receiver cannot physically check the completeness of the requirements for securing and may be negligent in checking, as a result of which the container may begin to move uncontrollably within the gondola car body during transportation;

3 ) at the unloading station, the handling of gondola cars is also associated with increased labor intensity and the need to clean up the remains of bars and pneumatic casings. Such work with wooden blocks and a hammer does not correspond to modern ideas about sparsely populated, digital and reliable logistics [10];

4) when placing a container on the floor of a gondola car, situations often arise when the container does not lean evenly on 4 corners due to unevenness of the floor and the lack of the required number of linings (as a result of negligence or carelessness of loaders).

In case of improper positioning and fastening of the container in the gondola car, dangerous disturbances in the weighting of the car occur, which leads to unpredictability of the car's behavior in motion, and the risk of defects in the undercarriage, the container body and fraught with crashes or minor malfunctions increases. 
This provision contradicts the Technical Conditions for Stowing and Securing Cargo in Wagons and Containers No. TSM-943 dated May 27, 2003, and also does not comply with the provisions of clause 9.3.4 "Railroad transportation" of state standard ISO 3874-2008, which provides the following: "For to ensure the safety of transportation by rail, containers must be supported on the railway platform with only all four lower corner fittings or only with support pads at the base of the container structure. " Containers shall be secure to the rail platform with all four lower corner fittings by means of universal cones that prevent sliding and tipping over due to longitudinal and lateral forces, or by pivoting head stoppers, or by other means complying with the requirements of the said standard. In addition, to ensure security, the document regulates that [11]:

- fastening devices must be clearly visible;

- all intermediate fasteners must be retracted or removed;

- before the vehicle starts to move, the fastening of the container must be checked;

- before removing the container, all locking devices must be open.

State standard R ISO 3874-2008 approved and put into effect by order of the Federal Agency for Technical Regulation and Metrology dated July 1, 2008 No. 132-st. The standard is identical to the international standard ISO 3874: 1997 "Series 1 freight containers - Handling and securing" (ISO 3874: 1997 "Series 1 freight containers Handling and securing"). In this regard, it is obvious that the transportation of containers in open-top wagons in a suitable and safe technical condition by the methods specified in the LTC does not comply with the provisions of State all-union standard R ISO 3874-2008.

In the modern transport system, each transport product is assign a certain niche. In the future, when building a full-fledged container transport system, all the advantages that all types of modern modality of freight transportation provide will be realize.

A feature of the transportation of goods in containers is the need for the reverse loading of the container or the transportation of empty containers [12]. Analyzing the flow of containers, it can be revealed that in order to load cargo into a container, it must be delivered to the consignor from any "drain" (warehouse of empty containers), where the containers are based, by road or in multimodal communication. Thus, before the actual transportation of the client's cargo, the container starts to move and itself becomes the cargo, which requires the use of a fitting platform and / or road train. After loading by the shipper, the container is send to its destination. After unloading at the destination, the container operator looks for the cargo to be loaded back to the place of departure or, if it is not possible to attract the cargo promptly, sends the container back empty.

Thus, with any technology of container transportation by rail, the availability of return loading for the railway rolling stock in the form of a loaded or empty container is guarantee

Involvement of gondola cars in servicing container transportation could slightly improve the performance of gondola cars when servicing import traffic (due to the emergence of the possibility of introducing double operations in ports), but at the same time, the use of gondola cars in these directions can lead to a deterioration in the performance of the fleet of fitting platforms, the balance of direct and return transportation of containers will disappear and unreasonable empty runs will appear at the fitting platforms [13].

The most effective policy of the infrastructure owner may be the abolition of administrative restrictions on the transportation of containers in open wagons with the simultaneous introduction of discouraging measures aimed at preventing the implementation of such transportation on main routes and routes with significant container traffic [14].

As such measures can be used:

1) the establishment of a ban on the placement of such cars on trains that have a CP sign (accelerated container train), since the operation of terminals and freight stations is adjusted 
to the processing of these trains, and a decrease in their performance will have a detrimental effect on the work of the most important transport hubs and will hit all players market;

2) tariff discouragement of mass transportation of containers in open wagons. Introduction of a differentiated tariff system depending on the number of gondola cars with containers in the train;

3) tariff incentives for the transport of containers on specialized rolling stock;

4) development of new technologies for transporting containers as part of container trains. Mass implementation of container routing and the use of technologies such as "Freight Express" and "Cold Express".

The introduction of these measures will allow limiting the scope of efficiency of using gondola cars for the transportation of universal containers, to single shipments of a small number of containers.

On the $1520 \mathrm{~mm}$ gauge railway network, there is still a shortage of stations open for handling large-capacity 40-foot containers. However, even among these stations, only a few can boast of having regular container routes connecting them to ports or major transport hubs. For such places, the banal problem of increasing the convenience and versatility of transport services is currently more urgent, and the launch of container transportation in open wagons by wagon and group shipments will allow customers to more flexibly approach the shipment of small consignments of cargo and take advantage of double operations.

An increase in supply in the segment of the market for small container shipments can lead to the emergence of a synergistic effect - the emergence of a technological possibility of carrying out container transportation will increase the competitiveness of rail transport compared to road transport, which in turn, in the long term, can lead to the generation of high demand for container transportation and the organization of regular transportation of containers on specialized rolling stock.

\section{Discussion}

Considering the root cause of this discussion as the desire of car operators to diversify their business, we can talk about the importance of stimulating the development and procurement of innovative types of cars that allow realizing the advantages of intermodality, low cost of rail transportation and interoperability.

Loading a container into an open-top wagon equipped with fitting stops completely eliminates the problem of increased labor intensity and low-tech transportation.

To develop a balanced solution on the issue of loading and transporting large-tonnage containers in open wagons, it is necessary to conduct a structural analysis of the geography of container transportation by rail and road transport, and identify potential markets for such transportation.

The presence of an administrative ban leads to a decrease in the external competitiveness of railway transport and the departure of potential shippers to road transport.

The technology of transporting containers in gondola cars requires the use of additional resources of all stakeholders: the owner of the infrastructure, the carrier, the car operator, the terminal operator and the auditor. Additional operating costs for organizing such transportation limit and determine the target niche for such transportation as one-time or small container shipments to stations with insufficient container traffic to organize a regular container train.

Further development of the idea of the promising state of the rolling stock market as a universal, high-performance and reliable complex, it is worth paying attention to the proposals of the United Wagon Company (PJ SC "SCIENTIFIC AND PRODUCTION 
CORPORATION" UNITED WAGON COMPANY ") for the introduction of shift technology bodies. This technology allows the owner of the rolling stock to flexibly respond to market conditions, and using one carriage part to change the type of cargo body in a matter of minutes. The technology of swap bodies will give an impetus to the use of highly specialized universal containers, such as containers-dump cars, open-top containers and even rarer types of containers for Russia.

\section{References}

1. J. Majercak, S. Kudlac, M. Panak. Sustainable and Economically Efficient Five-point Supply Chain Management, in Proceedings of the 20th International Scientific Conference on Transport Means, 5-7 October 2016, Kaunas, Lithuania (2016)

2. A. Egorov, N. Pilipchuk, I. Khmelev, V. Shatokhin, A. Kovkin. World experience in the development of container traffic, in IOP Conference Series: Materials Science and Engineering, 1-5 October 2019, Kislovodsk, Russia (2019)

3. V. Persianov, E. Rudakova, A. Safronova, N. Pilipchuk. Trends in the Development of Corporate Ethics in the Company "DHL" and JSC "Russian Railways" in the Current Socio-Economic Conditions. in Advances in Intelligent Systems and Computing, 2227 May 2020, Novosibirsk, Russia, 2, 1116 (2020)

4. O. Pokrovskaya, N. Reshetko, M. Kirpicheva, A. Lipatov, D. Mustafin The study of logistics risks in optimizing the company's transportation process. in IOP Conference Series: Materials Science and Engineering, 1-5 October 2019, Kislovodsk, Russia, 698, 6 (2019)

5. O. Pokrovskaya, R. Fedorenko, E. Khramtsova. Formation Of Transport And Storage Systems. International Scientific Conference "Global Challenges and Prospects of the Modern Economic Development". (GCPMED), 06 - 08 December 2018, Samara, Russia (2018)

6. P. Kurenkov, O. Pokrovskaya, M. Anastasov, M. Sokolov, A. Bochkov. Study of the current state of the transport infrastructure of road and rail transport of the Russian Federation, in IOP Conference Series: Materials Science and Engineering, 1-5 October 2019, Kislovodsk, Russia, 698, 6 (2019)

7. A. Kurbatova, P. Kurenkov, A. Safronova, Yu. Tanaino. Selection of optimal supply schemes, in XII International Scientific Conference on Agricultural Machinery Industry, 10-13 September 2019, Rostov-on-Don, Russia (2019).

8. J. Gasparik, V. Luptak, P. Mesko, P. Kurenkov. Methodology for assessing transport connections on the integrated transport network. Komunikacie, 19, 2 (2017)

9. E. Majercakova, P. Majercak, J. Majercak. Logistics and New Trends in Supply Chain Management in Times of Economic Crisis, in 3rd International Conference on Education Reform and Management Innovation (ERMI 2015), 05-06 September 2015, Bangkok, Thailand, 78 (2015)

10. S. Kudlac, V. Stefancova, J. Majercak. Using the Saaty Method and the FMEA Method for Evaluation of Constraints in Logistics Chain, in 10th International Scientific Conference on Transportation Science and Technology. 04-05 May 2017, Vilnius, Lithuania, 187 (2017).

11. P. Kurenkov, A. Astafiev, O. Kaplina. Different exegesis of the concepts related to mixed transport. Komunikacie, 18, 2 (2016)

12. J. Majerčák, P. Majerčák. The impact of the dynamics of a train ride in a curve and its effect on a superstructure, in Transportation Research Procedia, 29-31 May 2019, Novy Smokovec, 40, (2019) 
13. M. Babin, M. Buda, J. Majercak. Terminals for Transportation of Dangerous Goods, in 16th International Conference on Transport Means, 25-26 October 2012, Kaunas, Lithuania (2012)

14. Ch. Hoare Interacting sequential processes, Moscow, USSR (1989) 